\title{
Deuterium permeation behavior through yttria-stabilized zirconia coating fabricated by magnetron sputtering
}

\author{
Riho Endoh $^{\mathrm{a}}$, Kazuki Nakamura ${ }^{\mathrm{a}}$, Hikari Fujita ${ }^{\mathrm{b}}$, Moeki Matsunaga ${ }^{\mathrm{a}}$, Keisuke Kimura ${ }^{\mathrm{a}}$, \\ Johann Riesch ${ }^{\mathrm{c}}$, Yoshimitsu Hishinuma ${ }^{\mathrm{d}}$, Takumi Chikada ${ }^{{ }^{*}}$ \\ ${ }^{a}$ Shizuoka University, 836, Ohya, Suruga-ku, Shizuoka 422-8529, Japan \\ ${ }^{b}$ The University of Tokyo, 7-3-1 Hongo, Bunkyo-ku, Tokyo 113-8656, Japan \\ ${ }^{c}$ Max-Planck-Institut für Plasmaphysik, D-85748 Garching, Germany \\ ${ }^{d}$ National Institute for Fusion Science, 322-6 Oroshi, Toki, Gifu 509-5292, Japan
}

\begin{abstract}
For the realization of a sufficient fuel cycle in a fusion reactor, tritium permeation barriers have been studied mainly using ceramics coatings to suppress tritium leakage through structural materials. In this study, the first trial of fabrication and characterization of yttria-stabilized zirconia (YSZ) coatings has been carried out. The YSZ coatings containing 4 mol\% $\mathrm{Y}_{2} \mathrm{O}_{3}$ were deposited on reduced activation ferritic/martensitic steels by radio-frequency magnetron sputtering devices in two different deposition modes. The coating fabricated in the metallic mode showed a lower density with many cracks, and deteriorated after annealing and deuterium permeation tests at $600{ }^{\circ} \mathrm{C}$. On the other hand, the coating fabricated in the poison mode showed relatively higher density, and did not deteriorate from the result of the deuterium permeation measurements at up to $600{ }^{\circ} \mathrm{C}$. These results suggest that the YSZ coating deposited in the poison mode would be applied as a tritium permeation barrier.
\end{abstract}

Keywords: Tritium, Permeation, Coating, Yttria-stabilized zirconia, Magnetron sputtering

\section{Introduction}

Since tritium has an extremely low concentration on earth, production and recovery of tritium are required in fusion reactor blankets. However, hydrogen isotopes such as tritium have high diffusivity in most metals at elevated temperatures $\left(>300^{\circ} \mathrm{C}\right)$, resulting in critical fuel loss at the blankets where the operating temperature is high. One of the solutions for the problems is to apply a tritium permeation barrier (TPB) on structural materials such as reduced activation ferritic/martensitic (RAFM) steels $[1,2]$. Ceramics such as zirconium oxide $\left(\mathrm{ZrO}_{2}\right)$ and yttrium oxide $\left(\mathrm{Y}_{2} \mathrm{O}_{3}\right)$ have been considered as candidate materials for TPB $[3,4]$. In particular, $\mathrm{ZrO}_{2}$ coatings showed high permeation reduction performance as well as high compatibility with liquid tritium breeders such as lithium-lead [5]. However, it was also found that the deterioration of the coating such as cracking occurred at high temperatures [3]. Meanwhile, yttria-stabilized zirconia (YSZ) produced by the addition of $\mathrm{Y}_{2} \mathrm{O}_{3}$ to $\mathrm{ZrO}_{2}$ has better thermal cycle stability and fracture toughness than $\mathrm{ZrO}_{2}[6,7]$. In general, the properties of YSZ bulks change depending on the amount of doping $\mathrm{Y}_{2} \mathrm{O}_{3}$ to $\mathrm{ZrO}_{2}$. When the amount of $\mathrm{Y}_{2} \mathrm{O}_{3}$ is less than $9 \mathrm{~mol} \%$, it is known that the YSZ can suppress crack propagation because of the volume expansion with the phase transformation [7]. On the other hand, when the amount is $9 \mathrm{~mol} \%$ or more, the crystalline phase of the YSZ is kept in a wide temperature range [6]. Accordingly, YSZ may have properties that can solve the problems of $\mathrm{ZrO}_{2}$ such as cracking. In the case of coating, however, the characteristics of YSZ such as crystal phase, grain structure, and heat resistance may change depending on the fabrication method, since little knowledge about YSZ coatings has been obtained. In this study, the YSZ coatings doped with $4 \mathrm{~mol} \% \mathrm{Y}_{2} \mathrm{O}_{3}$ in $\mathrm{ZrO}_{2}$ (4Y-YSZ) have been fabricated, and their applicability as TPB was investigated through structural analysis, annealing and deuterium permeation tests.

\section{Experimental}

\subsection{Sample fabrication and microstructural analysis}

Mirror-polished reduced activation ferritic/martensitic (RAFM) steel F82H (Fe-8Cr-2W) plates with dimensions of $25 \mathrm{~mm}$ in length, $25 \mathrm{~mm}$ in width and $0.5 \mathrm{~mm}$ in thickness were used as substrates. 4Y-YSZ coatings were fabricated by radio-frequency (RF) magnetron sputtering devices, UNIVEX 450 B, Leybold Vacuum and Discovery ${ }^{\circledR} 18$, Denton Vacuum, with two different deposition modes: the metallic and poison modes, respectively [8]. Both devices are located at Max-PlanckInstitut für Plasmaphysik. The composition of the target was $8 \mathrm{wt} \% \mathrm{Y}$ in $\mathrm{Zr}(99.9 \%$ purity) with $3 \mathrm{~cm}$ in diameter and $0.25 \mathrm{~cm}$ in thickness. In the metallic mode, the target is sputtered as metal ions and atoms, and sputtered $\mathrm{Zr}$ and $Y$ react with oxygen on the substrate. In the poison mode, owing to the high flow rate of oxygen, the surface of the target is oxidized and sputtered as oxides. The deposition rate of the poison mode is relatively lower than that of the metallic mode since ionic bonds are generally stronger than metallic ones. Table 1 shows the details of the coating fabrication parameter. The deposition time was set to obtain the desired coating thickness: $800 \mathrm{~nm}$. The coating was fabricated at room temperature. The coating thickness was decided from the perspective of surface coverage of the coating because pores might form when the coating thickness is too small [9]. 
The crystal structure of the samples was examined by X-ray diffraction (XRD, RINT-2200, Rigaku Corp.). Surfaces and cross-sections were observed using a fieldemission scanning electron microscope (FE-SEM, JSM$7100 \mathrm{~F}$, JEOL Ltd.) equipped with energy dispersive Xray spectroscopy (EDS) for elemental analysis. Both instruments are located at the National Institute for Fusion Science (NIFS). The cross-sections of the samples were faired using a cross-section polisher (IB-09020 CP, JEOL Ltd.). The depth profiles of atomic concentration were conducted by X-ray photoelectron spectroscopy (XPS, PHI 5000 VersaProbe, ULVAC-PHI, Inc.) located at The University of Tokyo. X-ray source was Al Ka (1486.6 eV), and the sample surface was sputtered using a $4 \mathrm{kV}$ Ar ion gun with a sputtering rate of approximately $20 \mathrm{~nm} \mathrm{~min}^{-1}$. Surface coverages of the coatings fabricated in the metallic mode were calculated with surface SEM images using Image $\mathrm{J}[10]$.

Table 1. Fabrication parameter of 4Y-YSZ coating.

\begin{tabular}{ccc}
\hline Apparatus & $\begin{array}{c}\text { UNIVEX 450B } \\
\text { Leybold Vacuum }\end{array}$ & $\begin{array}{c}\text { Discovery }{ }^{\circledR} 18 \\
\text { Denton Vacuum }\end{array}$ \\
\hline Base pressure / Pa & $1.0 \times 10^{-4}$ & $5.0 \times 10^{-5}$ \\
$\begin{array}{c}\text { Oxygen ratio / \% } \\
\text { Power density } \\
/ \mathrm{W} \mathrm{L} \mathrm{L}^{-1}\end{array}$ & 1.7 & 13 \\
$\begin{array}{c}\text { Deposition rate } \\
/ \text { nm min }^{-1}\end{array}$ & 1.99 & 5.33 \\
Deposition mode & Metallic & 2.4 \\
\hline
\end{tabular}

\subsection{Annealing test}

A heat treatment was conducted for the samples to investigate thermal resistance. The test condition was considered according to Ref. [11-13]. The annealing temperature was $600^{\circ} \mathrm{C}$ because the deterioration of the $\mathrm{ZrO}_{2}$ coating such as cracking occurred at the temperature in the previous research [3]. Considered above, the annealing test was performed at $600{ }^{\circ} \mathrm{C}$ for $24 \mathrm{~h}$ in a high vacuum $\left(\sim 10^{-6} \mathrm{~Pa}\right)$ in this study.

\subsection{Deuterium permeation measurement}

Deuterium permeation behavior in the coatings was investigated by a gas-driven permeation method. The deuterium permeation equipment and the experimental procedure are described in detail in Ref. [14]. The sample was mounted on a pair of the sample holders with the coated side facing the upstream side, and the driving deuterium pressure was set at $10-80 \mathrm{kPa}$ in the temperature range of $300-600^{\circ} \mathrm{C}$. The tests started at 300 ${ }^{\circ} \mathrm{C}$, and the test temperature was raised in sequence. Permeated deuterium through the coating was measured with a quadrupole mass spectrometer (QMS) installed at the downstream side, and the deuterium permeation flux $J\left(\mathrm{~mol} \mathrm{~m} \mathrm{~m}^{-2} \mathrm{~s}^{-1}\right)$ was calculated using a calibration factor obtained from a deuterium standard leak. The deuterium permeation flux $J$ with a thickness of $d(\mathrm{~m})$ is expressed by the following equation [14]:

$$
J=P \frac{p^{n}}{d}
$$

where $P\left(\mathrm{~mol} \mathrm{~m}^{-1} \mathrm{~s}^{-1} \mathrm{~Pa}^{-n}\right)$ is the permeability and $p(\mathrm{~Pa})$ is driving pressure. The pressure exponent $n$ obtained by a fitting curve of the permeation flux as a function of driving pressure depends on the permeation process. It is known that when the rate-determining process is diffusion (atomic process) in the sample, the exponent shows 0.5 , while when the rate-determining process is a surface reaction (molecular process), the exponent shows unity [2]. For the evaluation of TPB efficiency, a permeation reduction factor (PRF) was calculated dividing the permeation flux of a bare substrate by that of a coated one.

\section{Results and discussion}

\subsection{Structural analysis before the tests}

Figs. 1 and 2 show surface and cross-sectional SEM images of $4 \mathrm{Y}$-YSZ coating samples fabricated in the metallic and poison modes. The coating fabricated in the metallic mode showed a porous structure with many gaps, while the coating fabricated in the poison mode was dense. The density of the coatings was estimated from the mass change before and after the deposition and the coating thickness: $3.99 \mathrm{~g} \mathrm{~cm}^{-3}$ in the metallic mode and $5.35 \mathrm{~g} \mathrm{~cm}^{-}$ 3 in the poison mode. Cross-sectional SEM images show columnar structures for both coatings. The elemental ratios of $\mathrm{Zr}$ to $\mathrm{Y}(\mathrm{Zr} / \mathrm{Y})$ for the coatings were analyzed by EDS: $11.3 \pm 0.2$ in the metallic mode and $11.7 \pm 0.2$ in the poison mode. The ideal $\mathrm{Zr} / \mathrm{Y}$ ratio for $4 \mathrm{Y}-\mathrm{YSZ}$ is 11.5 , which indicates the composition of the coatings was as expected. These results suggest that the deposition mode
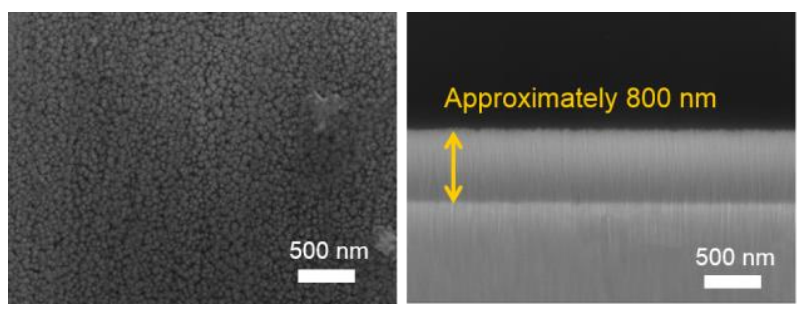

Fig. 1. Surface and cross-sectional SEM images of the 4YYSZ coating fabricated in the metallic mode.
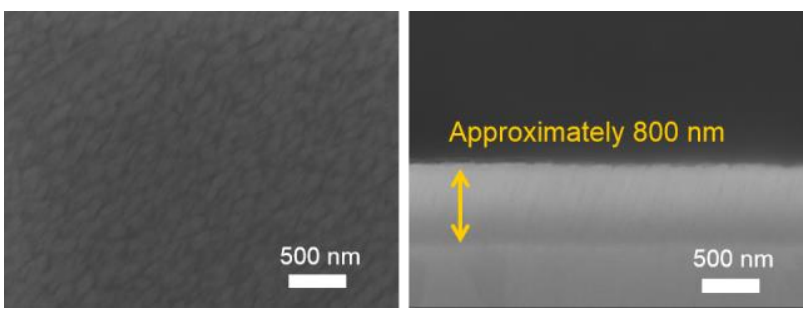

Fig. 2. Surface and cross-sectional SEM images of the 4YYSZ coating fabricated in the poison mode. 


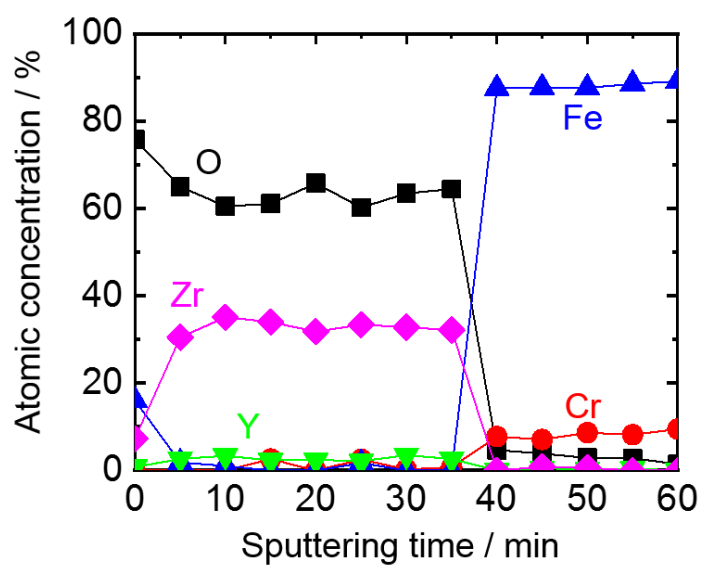

Fig. 3. XPS depth profile of $4 Y-Y S Z$ coating fabricated in the poison mode.

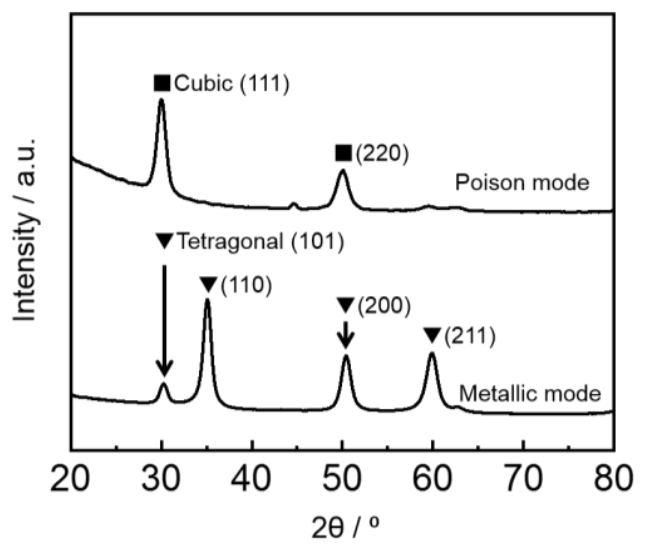

Fig. 4. XRD spectra of the $4 Y-Y S Z$ coating samples.

mainly affected the density of the coating.

The XPS depth profiles of the 4 Y-YSZ coating sample fabricated in the poison mode are shown in Fig. 3. The coating thickness estimated by the sputtering rate was consistent with the results from cross-sectional observation. Furthermore, the elemental composition ratio of $\mathrm{Zr}$ to $\mathrm{Y}$ was calculated from the peak intensity of each element, and nearly the same as that of the target. Therefore, it was confirmed that the $\mathrm{ZrO}_{2}$ layer containing $4 \mathrm{~mol} \% \mathrm{Y}_{2} \mathrm{O}_{3}$ was successfully fabricated on the substrate. It should be noted that considering the comparable $\mathrm{Zr} / \mathrm{Y}$ ratio by EDS, the coating sample fabricated in the metallic mode would also have a similar depth profile, although XPS analysis was not performed.

XRD spectra of the 4Y-YSZ coatings fabricated in both modes are shown in Fig. 4. The peaks were identified by the ICDD reference file number for cubic zirconium yttrium oxide: 01-077-2112 [16] and tetragonal zirconium yttrium oxide: 04-008-7255 [17]. The coatings fabricated in the metallic and poison modes were dominated by tetragonal and cubic, respectively. The average grain size of the coatings estimated from full width half maximum of the highest peak and Scherrer equation [18] were approximately $8 \pm 1 \mathrm{~nm}$ for the metallic mode and $7 \pm 1$ $\mathrm{nm}$ for the poison mode, respectively. In terms of the grain size, differences were not confirmed depending on the deposition modes. From these results of structural analysis, it was suggested that a coating with a dense microstructure is fabricated by controlling the deposition conditions.

\subsection{Annealing test}

Fig. 5 shows surface SEM images of the 4Y-YSZ coating fabricated in both modes after the annealing test. Cracks spread throughout the coating fabricated in the metallic mode, while no cracks were observed on the coating fabricated in the poison mode. The average grain size of both coatings was approximately $8 \pm 1 \mathrm{~nm}$. These results indicate that the coating fabricated in the metallic mode had less resistance to compressive stress and thermal expansion than that of the poison mode.

\subsection{Deuterium permeation behavior}

Temperature dependence of deuterium permeation flux for the 4Y-YSZ coating samples is shown in Fig 6. In the measurements at 300 and $400{ }^{\circ} \mathrm{C}$, both samples showed almost the same permeation flux as the substrate. The PRFs at 300 and $400{ }^{\circ} \mathrm{C}$ were approximately 1.0 and 2.0 , respectively. The low PRFs would be attributed to insufficient crystallization of the coatings, resulting in the existence of many fast permeation paths. The permeation fluxes of both samples decreased significantly as the test temperature increased from $400{ }^{\circ} \mathrm{C}$ to $500{ }^{\circ} \mathrm{C}$, and the PRF was about 10. It was considered that the number of the deuterium permeation paths decreased due to crystallization and grain growth. There was no significant difference in the deuterium permeation behavior between the coatings fabricated in the metallic and poison modes at the permeation measurements from $300{ }^{\circ} \mathrm{C}$ to $500{ }^{\circ} \mathrm{C}$. A clear difference between the metallic and poison modes was seen in the measurement at $550{ }^{\circ} \mathrm{C}$. The permeation flux did not decrease significantly in the test of the sample fabricated in the metallic mode, and the PRF was approximately 20 . On the other hand, in the poison mode, the permeation flux further decreased to approximately $20 \%$ from that at $500{ }^{\circ} \mathrm{C}$, and the PRF was 54 . From these results, the coating fabricated in the metallic mode deteriorated such as crack formation, or crystallization and grain growth less progressed at $550{ }^{\circ} \mathrm{C}$. Fig. 7 indicates the temporal change of the deuterium permeation flux at $600{ }^{\circ} \mathrm{C}$ and $80 \mathrm{kPa}$ for $4 \mathrm{Y}-\mathrm{YSZ}$ coatings fabricated in the metallic and poison modes. The
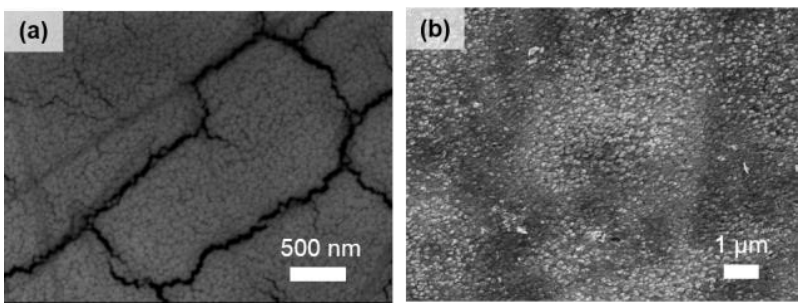

Fig. 5. Surface SEM images of 4Y-YSZ coating samples fabricated in the metallic (a) and poison (b) mode after annealing test. 


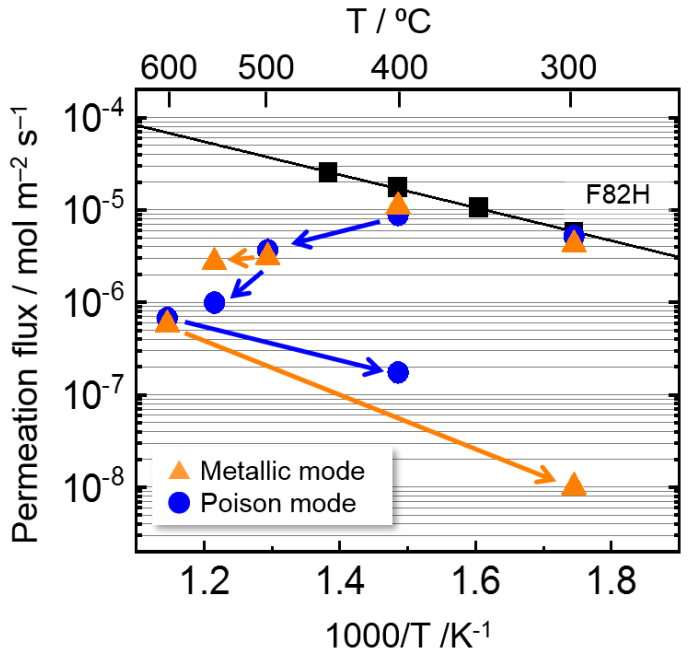

Fig. 6. Arrhenius plots of deuterium permeation flux for $4 \mathrm{Y}-$ YSZ coating samples.

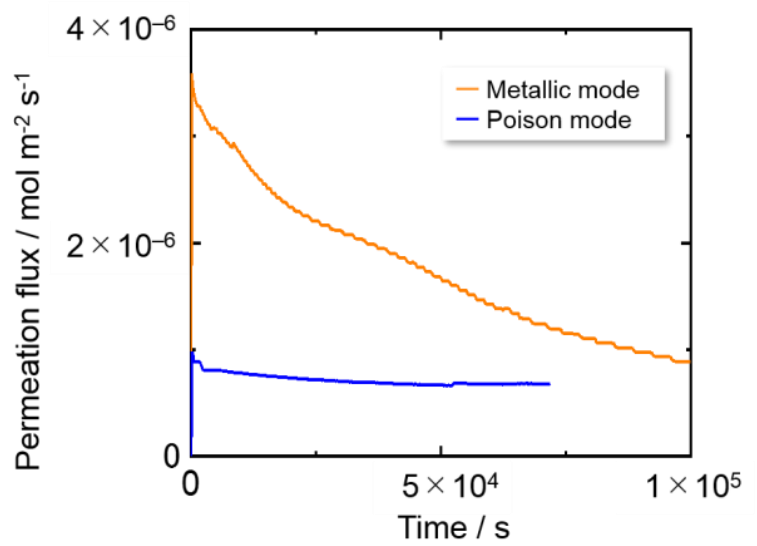

Fig. 7. Temporal change of deuterium permeation flux at 600 ${ }^{\circ} \mathrm{C}$ and $80 \mathrm{kPa}$ for $4 \mathrm{Y}-\mathrm{YSZ}$ coating samples.

sample fabricated in the metallic mode took a longer time to reach a steady-state than that in the poison mode. The coating fabricated in the metallic mode might be oxidized because the behavior that the permeation flux continued to decrease for a long time was seen in common among oxidizing samples. Besides, both samples showed a similar PRF of about 100; however, the exponents of the driving pressure shown in Eq. (1) were different as shown in Fig. 8. The coating fabricated in the metallic mode showed the exponent of nearly 1.0 , while the coating fabricated in the poison mode showed and the exponent of nearly 0.5 . In the coating deposited in the metallic mode, the surface-limited regime was assumed to be attributed to oxidation of the substrate-exposed area by cracking of the coating. Therefore, not only the coating but also the oxidized substrate at the cracked area would contribute to the permeation reduction performance. That means the coating would deteriorate at $600{ }^{\circ} \mathrm{C}$, and the high permeation reduction performance in the measurement at the last $300{ }^{\circ} \mathrm{C}$ might be due to the progress of the substrate oxidation. In contrast, the coating deposited in the poison mode showed the

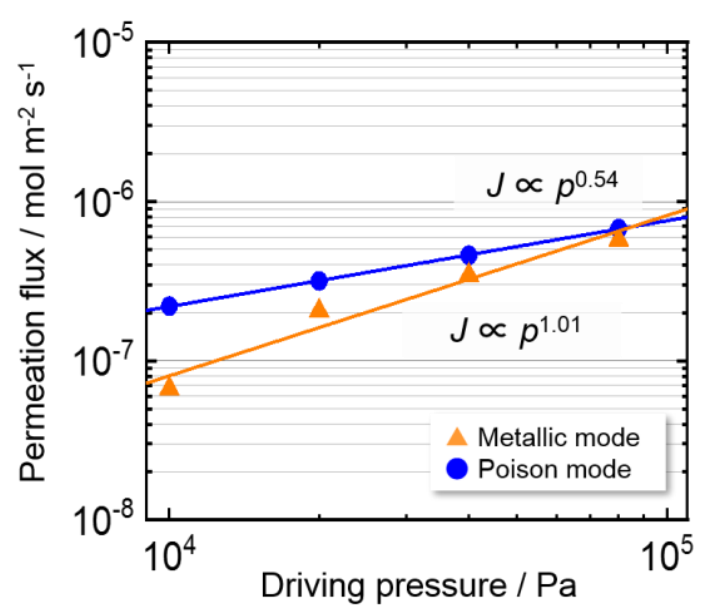

Fig. 8. Relationships between deuterium permeation flux and driving pressure for $4 \mathrm{Y}$-YSZ coating samples at $600{ }^{\circ} \mathrm{C}$.

diffusion-limited regime with the comparable PRF at 600 ${ }^{\circ} \mathrm{C}$ and the last $400{ }^{\circ} \mathrm{C}$, indicating that the coating would not deteriorate. Consequently, the YSZ coating fabricated in the poison mode can be a candidate for the TPB. Further parametric studies with increasing substrate temperature during deposition and fabrication of YSZ coatings with higher $\mathrm{Y}_{2} \mathrm{O}_{3}$ content are required for optimization.

\subsection{Structural analysis after the tests}

Fig. 9 shows surface SEM images of the 4Y-YSZ coating fabricated in both modes after the permeation tests. Cracks spread throughout the coating fabricated in the metallic mode as with the case after the annealing tests. Meanwhile, the coating fabricated in the poison mode did not form cracks. In addition to surface SEM images, the average grain sizes were estimated from full width half maximum of the highest peak in XRD spectra and Scherrer equation: approximately $8 \pm 1 \mathrm{~nm}$ for the metallic mode and $9 \pm 1 \mathrm{~nm}$ for the poison mode, respectively. A slight increase in the grain size of the coating deposited in the poison mode was confirmed. Therefore, only the coating would contribute to the high permeation reduction performance in the coating fabricated in the poison mode.

The surface SEM images processed by Image $\mathrm{J}$ to
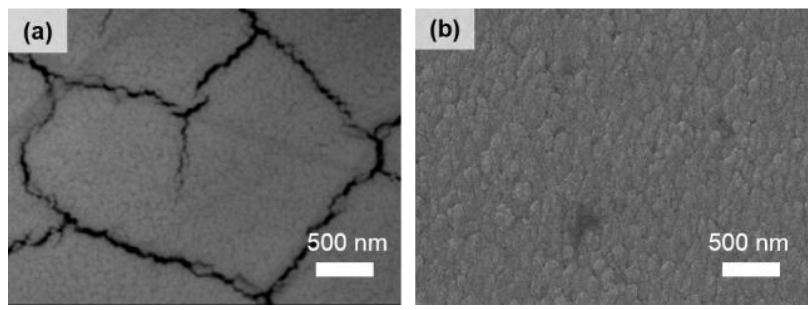

Fig. 9. Surface SEM images of 4Y-YSZ coating samples fabricated in the metallic (a) and poison (b) mode after permeation tests. 
evaluate surface coverage of 4Y-YSZ-coated samples fabricated in the metallic mode after the permeation and the annealing tests are shown in Fig 10. Surface coverages were calculated by the ratios of the red region to the whole for each sample. The surface coverages of the coatings after the permeation and the annealing tests were 94.5 and $93.9 \%$, respectively. It was found that cracks in the coating fabricated in the metallic mode accounted for approximately $6 \%$ in the whole sample at $600{ }^{\circ} \mathrm{C}$ regardless of whether deuterium existed. Fig. 11 shows calculated permeation fluxes through the coating as a function of surface coverage using the permeation data at 500,550 , and $600{ }^{\circ} \mathrm{C}$. The calculation method was described in detail in Ref. [19]. Comparison of the permeation flux between measured and calculated values using the surface coverage of $94.5 \%$ is shown in Table 2. The calculated permeation fluxes at 500 and $550{ }^{\circ} \mathrm{C}$ were similar to the measured ones. That means the cracks formed in the coating during the tests at 500 and $550{ }^{\circ} \mathrm{C}$. However, at $600{ }^{\circ} \mathrm{C}$, the calculated permeation flux was one order of magnitude larger than the measured one even though the coating had already deteriorated. In our previous study, oxide layers formed on the substrate decreased deuterium permeation by a factor of up to 150 [20]. Therefore, the difference between measured and
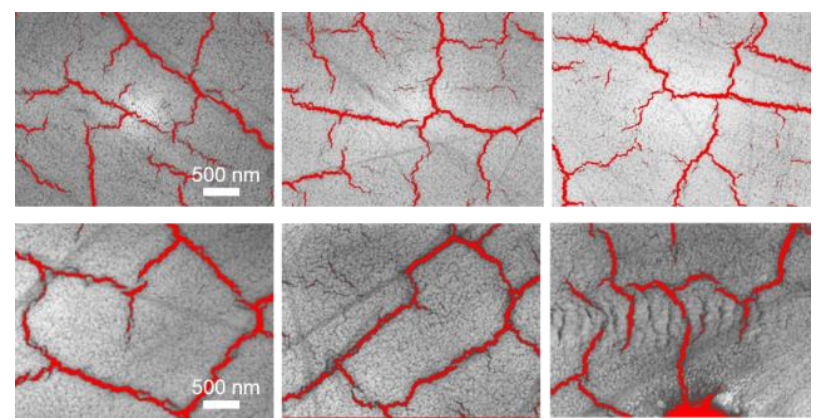

Fig. 10. Surface SEM images processed by Image J for $4 \mathrm{Y}$ YSZ-coated samples fabricated in the metallic mode after permeation (upper side) and annealing (under side) tests.

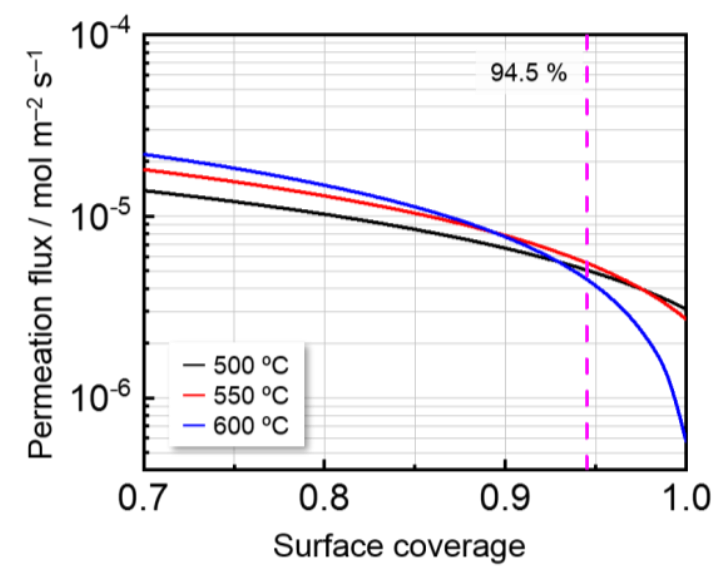

Fig. 11. Calculated permeation fluxes at 500, 550, and $600{ }^{\circ} \mathrm{C}$ through the $4 \mathrm{Y}-\mathrm{YSZ}$ coating fabricated in the metallic mode.
Table 2. Measured and calculated permeation fluxes at each temperature with the coating of $94.5 \%$ surface coverage.

\begin{tabular}{ccc}
\hline $\begin{array}{c}\text { Test temperature } \\
/{ }^{\circ} \mathrm{C}\end{array}$ & $\begin{array}{c}\text { Measured flux } \\
/ \mathrm{mol} \mathrm{m}^{-2} \mathrm{~s}^{-1}\end{array}$ & $\begin{array}{c}\text { Calculated flux } \\
/ \mathrm{mol} \mathrm{m}^{-2} \mathrm{~s}^{-1}\end{array}$ \\
\hline 500 & $3.08 \times 10^{-6}$ & $5.06 \times 10^{-6}$ \\
550 & $2.72 \times 10^{-6}$ & $5.53 \times 10^{-6}$ \\
600 & $5.76 \times 10^{-7}$ & $4.50 \times 10^{-6}$ \\
\hline
\end{tabular}

calculated values of the permeation flux might be attributed to the substrate oxidation. From the discussion above, it can be said that cracks that reached the substrate formed in the coating fabricated in the metallic mode during the permeation tests at 500 and $550{ }^{\circ} \mathrm{C}$, and then showed the high permeation reduction performance at 600 ${ }^{\circ} \mathrm{C}$ because the substrate-exposed area might be oxidized by impurity oxygen.

\section{Summary}

In this study, YSZ coatings with $4 \mathrm{~mol} \% \mathrm{Y}_{2} \mathrm{O}_{3}$ were fabricated by RF magnetron sputtering in two different modes, and their applicability as TPB was investigated through structural analysis, annealing test, and deuterium permeation measurements. The coating fabricated in the metallic mode had many gaps and a relatively low density. The deuterium permeation measurement showed the PRF of about 100 at $600{ }^{\circ} \mathrm{C}$; however, the performance would be attributed to oxidation of the exposed substrate surface. The coating fabricated in the poison mode demonstrated a relatively high density as well as comparable permeation reduction performance at $600{ }^{\circ} \mathrm{C}$. The rate-determining process of the deuterium permeation proved that the coating did not deteriorate at up to $600{ }^{\circ} \mathrm{C}$. As a consequence, the YSZ coating fabricated by RF magnetron sputtering in the poison mode would be applied as a TPB.

\section{Acknowledgments}

This work was supported by the Japan-U.S.-EU nuclear student international exchange program for Atomic Energy Society of Japan, JSPS KAKENHI Grant Number 19H01873, the general collaboration research with the National Institute for Fusion Science (NIFS18KEMF119), and Nanotechnology-Platform-Project by the Ministry of Education, Culture, Sports, Science and Technology Japan, Grant Number JPMXP09A19UT0260.

\section{References}

[1] G.W. Hollenberg et al., Tritium/hydrogen barrier development, Fusion Engineering and Design 28 (1995) 190-208.

[2] Ch. Linsmeier et al., Development of advanced high heat flux and plasma-facing materials, Nucl. Fusion 57 (092007) (2017) 60 .

[3] T. Chikada et al., Fabrication technology development and 
characterization of tritium permeation barriers by a liquid phase method, Fusion Engineering and Design 136 (A) (2018) 215-218.

[4] T. Chikada et al., Crystallization and deuterium permeation behaviors of yttrium oxide coating prepared by metal organic decomposition, Nuclear Materials and Energy 9 (2016) 529-534.

[5] M. Matsunaga et al, Lithium-lead corrosion behavior of erbium oxide, yttrium oxide and zirconium oxide coatings fabricated by metal organic decomposition, J. Nucl. Mater. 511 (2018) 534-543.

[6] H.G. Scott, Phase relationships in the zirconia-yttria system, Journal of Materials Science 10 (1975) 1527-1535.

[7] J. Robert Kelly et al., Stabilized zirconia as a structural ceramic: An overview, Dental Materials 24 (2008) 289-298.

[8] A.F. Jankowski et al., Reactive sputter deposition of yttriastabilized zirconia, Surface and Coatings Technology 67 (1) (1995) 126-131.

[9] T. Chikada et al., Microstructure change and deuterium permeation behavior of erbium oxide coating, Journal of Nuclear Materials 417 (2011) 1241-1244.

[10] Rasband, W.S., ImageJ, U. S. National Institutes of Health, Bethesda, Maryland, USA, http://rsb.info.nih.gov/ij/, 19972012.

[11] T. Matsui et al., Preparation and properties of yttriastabilized zirconia thin films by $\mathrm{rf}$ magnetron reactive sputtering, Technical report of IEICE CPM2001-114 (2001) 131-135.

[12] Y. Mao et al., The influence of annealing on yttrium oxide thin film deposited by reactive magnetron sputtering: Process and microstructure, Nuclear Materials and Energy 10 (2017) 1-8.

[13] K. Nakamura et al., Iron-ion irradiation effects on microstructure of yttrium oxide coating fabricated by magnetron sputtering, Fusion Engineering and Design 146 (B) (2019) 2031-2035.

[14] T. Chikada et al., Deuterium permeation behavior of erbium oxide coating on austenitic, ferritic, and ferritic/martensitic steels, Fusion Engineering and Design 84 (2009) 590-592.

[15] E. Serra et al., Influence of traps on the deuterium behavior in the low activation martensitic steels F82H and Batman, Journal of Nuclear Materials 245 (1997) 108-114.

[16] H. Horiuchi et al., Time-of-flight neutron-diffraction study of a single-crystal of yttria-stabilized zirconia, $\mathrm{Zr}(\mathrm{Y}) \mathrm{O}_{1.862}$, at high-temperature and in an applied electrical field, Acta Crystallographica Section B-Structural Science 40 (1984) 367-372.

[17] C.J. Howard et al., Structures of $\mathrm{ZrO}_{2}$ polymorphs at room temperature by high-resolution neutron powder diffraction, Acta Crystallographica B (1988) 116-120.

[18] A. L. Patterson, The Scherrer formula for X-ray particle size determination, Physical Review Journals Archive 56 (1939) 978-982.

[19] T. Chikada et al., Modeling of tritium permeation through erbium oxide coatings, Fusion Science and Technology 60 (2011) 389-393.

[20] T. Chikada et al., Surface oxidation effect on deuterium permeation in reduced activation ferritic/martensitic steel F82H for DEMO application, Fusion Engineering and 